\title{
ICONOGRAFIA NUMISMÁTICA: OS DOBRÕES DE OURO CUNHADOS NA CASA DA MOEDA DE VILA RICA, MINAS GERAIS (1724-1727)
}

\author{
Felipe Ribeiro Bittencourt ${ }^{1}$
}

\section{RESUMO}

A Casa da Moeda do Brasil esteve estabelecida na Província de Minas Gerais por poucos anos no início do século XVIII, durante o auge da produção de ouro no Brasil. Em Vila Rica, atual Ouro Preto, foram cunhadas as moedas da famosa série dos Dobrões, sendo a moeda de 20.000 réis a de maior valor intrínseco já circulada em todo o mundo. Este artigo analisa todos os símbolos presentes nesta série numismática, correlacionando-os com a situação política e econômica da época, bem como pondera como os ícones nessas moedas refletiam o poder do Rei e da religião nas Minas Setecentistas influenciando a própria construção da identidade do brasileiro.

Palavras-chave: Numismática; iconografia; Dobrões; ouro; Vila Rica

\section{ABSTRACT}

The Brazilian Mint Facility was established at Minas Gerais' Province for just a few years in the beginning of the XVIII century, during the gold peak production in Brazil. In Vila Rica, today Ouro Preto, the famous Dobrões coin series was minted, been the 20,000 réis coin known as the one with the highest intrinsic value ever circulated in the world. This article analyzes all symbols presented in this numismatic series correlating them with the political and economical situation of the time. It also considers how icons from those coins reflected the King's and Religion's power in the eighteenth-century Minas and influenced the Brazilian identity construction.

Keywords: Numismatic; iconography; Dobrões; gold; Vila Rica.

\section{RESUMEN}

La casa de la moneda brasileña se estableció en la Provincia de Minas Gerais por unos pocos años en los comienzos del siglo XVIII, durante el pico de producción de oro en Brasil. En Vila Rica, actual Ouro Preto, la famosa serie de monedas Dobrões fue acuñada, siendo la moneda de 20.000 réis conocida como la de más alto valor intrínseco ya circulada en todo el mundo. Este artículo analiza todos los símbolos presentados en esta serie numismática correlacionándolos con la situación política y económica de la época. También considera cómo los iconos de las monedas reflejaban el poder del rey y de la religión en las Minas del siglo XVIII influyendo en la construcción de la identidad brasileña.

Palabras-clave: Numismática; iconografia; Dobrões; oro; Vila Rica

${ }_{1}$ PhD, é Eng. Civil, Mestre e Doutor em Meio Ambiente pela UFMG e graduando em História pelo Centro Universitário Clarentiano. Ex-pesquisador visitante do Environmental Change Institute da Universidade de Oxford/Inglaterra, Felipe é desde 2013 professor visitante na UFMG. Endereço: Av. Antônio Calos, 6627-DESA. Belo Horizonte/MG. Tel. (31)3401-1074. Email: feliperb@gmail.com 


\section{Revista de Arqueologia Pública}

\section{Introdução}

Este artigo aborda o tema da iconografia numismática, especificamente da série de moedas de ouro dos Dobrões cunhada na Casa da Moeda de Vila Rica, atual cidade de Ouro Preto, Minas Gerais, entre os anos de 1724 e 1727.

Apesar dessa série de moedas ser mundialmente conhecida no mercado numismático, pouco foi discutido até então sobre os símbolos presentes nessas moedas. Assim, busca-se aqui interpretar os significados desses símbolos e inferir sobre suas influências.

A partir da Escola dos Annales, a Nova História passou a abordar um conjunto maior de fontes históricas. As moedas tornaram-se então uma interessante fonte de pesquisa. Contudo, ainda hoje, poucos são os que analisam os símbolos presentes na numismática nacional, mesmo nas cédulas e moedas correntes. Essa pesquisa tem, portanto, a intenção de explorar essa "nova" fonte de informações, buscando comprovar a hipóteses de que os símbolos presentes nas moedas refletem o poder e influenciam a formação da identidade de um povo.

O recorte histórico escolhido foi a cidade de Vila Rica, atual Ouro Preto, que recebeu a Casa da Moeda entre os anos de 1724 a 1735. A escolha desse recorte deve-se principalmente a dois motivos: (i) a substancial quantidade de ouro produzida na região e (ii) o fato de lá ter sido cunhada a moeda de maior valor intrínseco já circulada no mundo. Enquanto o primeiro motivo reflete todo um sistema de exploração colonial, o segundo ilustra a importância e grandeza da numismática mineira.

A análise se baseia inicialmente em uma profunda revisão bibliográfica do discurso sobre as funções e simbolismos da numismática. Em seguida é abordado o contexto histórico das Minas setecentista, com foco na produção de ouro e cobrança de impostos, como o quinto, pelo Reino. Essas duas abordagens são então combinadas em uma análise detalhada dos ícones presentes nos Dobrões na tentativa de elucidar o significado, muitas vezes, subliminar existente nesses símbolos.

Como a série de Dobrões possui a mesma característica simbólica em cada uma de suas 7 (sete) moedas, o presente estudo analisou a moeda de $20 \$ 000$ (vinte mil réis) como referência. Tal moeda já foi e ainda é conhecida como Dobrão. Inicialmente são identificados e comentados todos os símbolos presentes no anverso da moeda e posteriormente o mesmo é feito para seu reverso.

Pretende-se, a partir do entendimento de tais símbolos, discutir como os mesmos refletem o momento político, econômico e religioso da época, como fortaleciam o poder do 


\section{Revista de Arqueologia Pública}

reino e, finalmente, como construíam inconscientemente a identidade de um povo.

Os objetivos específicos são, portanto: (i) analisar os símbolos presentes nas moedas cunhadas em Vila Rica entre 1724 e 1727; (ii) correlacionar tais símbolos com a situação política, econômica e religiosa da época e (iii) indicar como tais símbolos refletiam o poder presente do Rei e como auxiliavam para a formação da identidade do brasileiro.

\section{Iconogragria numismática e os dobrões}

A iconografia é uma fonte de pesquisa histórica. Segundo Mauad (1997: 309), "como leitura dos ícones ou de imagens, os estudos iconográficos habilitam o historiador de uma interpretação mais ampla dos fenômenos de representação social, para além daquilo que conscientemente as sociedades passadas deixaram como legado". Assim, a iconografia auxilia o pesquisador em seus estudos, possibilitando-o verificar outros aspectos que não se limitem aos documentos escritos.

A numismática é uma das disciplinas que auxiliam os estudos a respeito do passado. Ela traz à luz da história uma rica fonte de informação ao se dedicar ao estudo de moedas, cédulas e medalhas. Os símbolos presentes na numismática refletem a elite dominante e a ideologia governamental. Tais ícones empregados são símbolos de poder e formadores de identidade (MAGNUS, 2001; SILVEIRINHA, 2004; RAMOS, 2012).

De acordo com diversos autores como Gooch (2011), Blackborn (2008), Parry e Bloch (1989), as imagens e inscrições presentes em uma moeda fornecem uma poderosa versão da imagem de um rei, pois são um produto oficial do governo, sancionado pelo próprio rei ou pelo mais alto nível de governo. As moedas são, portanto, reflexo dessa autoridade.

As moedas começaram a ser cunhadas em metais na Ásia Menor, provavelmente nos séculos VII ou VIII antes da era cristã. Na arqueologia numismática a dúvida se a origem foi no Reino da Lídia ou no de Argos durou várias décadas. Segundo Heródoto, foram os lídios os primeiros a cunhar moedas em outro e prata, contudo o lexicólogo Polux concluiu ser muito difícil saber a qual dos dois se devia atribuir esse mérito (COIMBRA, 1956). Florenzano (2001), após extensa pesquisa e análise crítica arqueológica e literária, finalmente definiu a origem como sendo a Reino da Lídia, onde hoje é localizada a Turquia.

No Brasil, havia poucas moedas em circulação até o século XVII. Houve uma pequena cunhagem de moedas em Pernambuco pelos holandeses entre 1645 e 1646, contudo, de um modo geral, as moedas em circulação eram provenientes de Portugal. Somente em 1694, foi instalada a Casa da Moeda da Bahia, a primeira casa monetária em 


\section{Revista de Arqueologia Pública}

solo brasileiro (CARLAN, 2006). A localização das Casas da Moeda passou a acompanhar o desenvolvimento do país de modo a reduzir os riscos de roubo. Assim, quatro anos depois, essa Casa da Moeda foi transferida para o Rio de Janeiro, onde permaneceu apenas até o ano de 1700, quando foi transferida para Recife. Em 1702, ela retornou ao Rio de Janeiro. Já em 1714, foi criada uma nova Casa da Moeda em Salvador e, em 1924, foi instalada a Casa da Moeda de Vila Rica, a qual foi extinta em 1935 (GONÇALVES, 1984).

As Casas de Fundição e Moeda de Vila Rica, que funcionaram entre 1724 e 1735, cunharam mais moeda do que as Casas da Moeda de Lisboa e do Rio de Janeiro juntas (CARRARA, 2010: 217). Tal fato deve-se principalmente à produção ouro nas minas da região, que já era bem significativa na época. O próprio Governador-Geral do Brasil já afirmava acerca das minas de ouro, em documento datado de 19 de junho de 1706, que "enquanto o mundo durar, se não poderão extinguir" (COIMBRA, 1956: 543). Na Casa da Moeda de Vila Rica, foram cunhados os Dobrões entre os anos de 1724 e 1727. Trata-se de moedas de ouro de 400, 1.000, 2.000, 4.000, 10.000 e 20.000 réis. A moeda de $20 \$ 000$ (vinte mil réis - figura 1) pesa 53,78 gramas de ouro e possui $91,7 \%$ de pureza. Ela é considerada a moeda de maior valor intrínseco já circulada no mundo.

a)

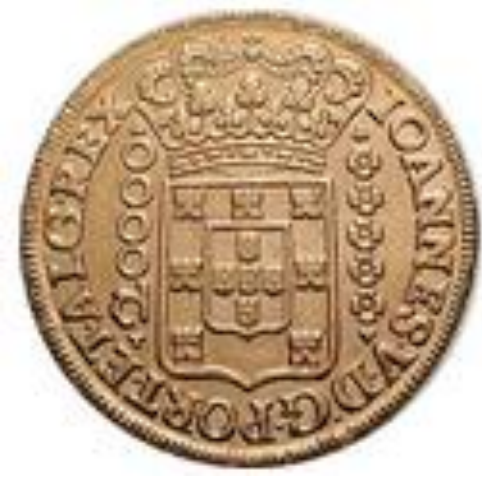

b)

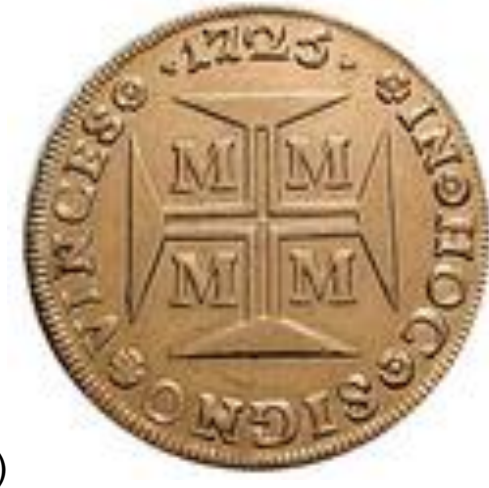

Figura 1: Dobrão de Ouro de 20\$000: a) anverso mostrando escudo das armas e coroa portuguesa; b) reverso mostrando Cruz de Cristo e letra monetária $\mathrm{M}$, em referencia à Casa da Moeda de Minas Gerais. FONTE: Moedas do Brasil, 2014.

\section{Análise do discurso sobre funções e simbolismos da numismática}

Carlan (2005) estudou sobre como a arte monetária romana era reflexo de uma propaganda. Segundo ele, as amoedações emitem mensagens do poder de um soberano emissor. O próprio metal precioso no qual uma moeda é cunhada veicula também a ideologia comum a uma civilização. As suas legendas e tipos refletem a estrutura mental de um povo, como também retratam o fato vivido. Segundo ele:

Os símbolos que habitam a numismática estão dotados sempre de 


\section{Revista de Arqueologia Pública}

uma clara organização hieroglífica, pois procedem do fato de que essas imagens difundidas se articulam sempre com o idioma figurado, no qual o poder se expressa secularmente. Trata-se, segundo de la Flor $^{2}$, do surgimento de representações da órbita de ação do poder, chegando ao ponto em que a numismática pode ser definida 'como um monumento oficial a serviço do Estado' (CARLAN, 2005: 169).

Em estudo mais recente, Carlan indica que a iconografia numismática e toda a sua simbologia aparece de fato como testemunho mais evidente do imaginário de uma determinada civilização. Ele ainda caracteriza a moeda como:

uma excelente fonte, pois, a partir de sua análise, encontramos diversos aspectos que abrangem a série na sua totalidade. Ou seja, aspectos políticos, estatais, jurídicos, religiosos, econômicos, mitológicos, estéticos. Podendo informar sobre os mais variados retrospectos de uma sociedade, ela testemunha determinadas relações culturais importantes para o historiador (CARLAN, 2015: 6).

Pela análise desses dois trechos de Carlan, pode-se então considerar a moeda como um instrumento a serviço do Estado para fortalecimento do poder. A moeda é, portanto, uma fonte histórica e possui elementos dos mais diversos que ajudam a compreender o contexto do momento de sua cunhagem.

Para Berg (2014), a moeda é utilizada como um forte elemento de propaganda de uma nação. Cerulo (1989) corrobora com essa visão afirmando que:

[...] desde o surgimento do Estado-nação, líderes políticos têm criado e usado símbolos nacionais (bandeiras, hinos, lemas, moedas, constituições, feriados) para direcionar a atenção pública, integrar cidadãos, e motivar a ação pública. [...] símbolos nacionais são comissionados, selecionados e projetados pelas elites políticas da nação, numa relação entre controle social e estrutura simbólica [...], elas "transformam" esses símbolos com referência às condições sociais que elas expressam e com os fins que elas desejam [...], pois buscam o controle sócio-político (CERULO, 1989: 77-79).

Com efeito, a propaganda é também um dos papéis centrais da numismática. Tal propaganda é conscientemente construída pela elite e possui função de controle social. $\mathrm{Na}$ verdade a numismática não pode ser vista como único ou principal agente dessa função. Ela é apenas um dos agentes dentro de um contexto mais amplo de esforço contínuo pela

\footnotetext{
${ }^{2}$ FLOR, Fernando R. de La. Emblemas Lectures de La Imagem Simbólica. Madrid: Alianza Editorial,
} 1995: 183. 


\section{Revista de Arqueologia Pública}

manutenção de poder. Ademais, a propaganda não é a único papel das moedas.

Luís Chaves, do Museu Etnológico do Porto refletiu sobre os diversos papéis empregados pela moeda em seu trabalho intitulado "A Moeda na Etnografia":

A Arqueologia, a História e a Numismática estudam-na ao longo da trajetória em serviço do homem e nas manifestações dele para a tornar útil, material, espiritual, socialmente e bela na arte, significativa no simbolismo. [...] Teve, todavia, a moeda outros empregos e facultou novas sugestões. [...] Aparece-nos também, sob outros aspectos, como moeda que não deixa de o ser, em muitas utilizações populares: ora transformada em ostentação de posse, sem perder o valor pecuniário (na aplicação a trajes e adereços de ourivesaria); ora aproveitada, pelos sinais contidos nela, para práticas ou sentimentos religiosos e de superstição; ora ainda utilizada em jogos e diversões. E tem de ser incluída a moeda política ou de insinuação política (CHAVES, 1956: 21).

Essa ampla visão de Chaves indica que o simbolismo e o uso das moedas vão além de propaganda e poder. Elas são usadas no dia a dia da população com várias funções: desde adereços de moda a jogos de lazer ou azar, de sinais de fortuna a sentimentos de religiosidade. Essa pluralidade de usos e significados que tornam a numismática uma rica e profunda fonte de pesquisa histórica, pois torna-se possível uma análise mais abrangente de diversas características que influenciam a própria construção de identidade de um povo em uma dada época.

Silverinha (2004) analisou a moeda e construção europeia a partir de uma abordagem identitária. Para ela, a moeda pode ser considerada um elemento de territorialização do Estado-Nação, bem como faz parte do processo de construção da identidade coletiva. Assim, "[...] a moeda pode ser entendida como comunicação, ligada não apenas aos seus aspectos 'funcionais' e 'abstratos' envolvidos na economia propriamente dita, mas também como ponto de ancoragem das representações nacionais" (SILVERINHA, 2004: 499).

Já Rinaldi e Nery (2009) realizaram uma análise semiótica do Real. Apesar de o estudo ter como foco as cédulas e ser destinado a um público da área de comunicação, sua conclusão é bastante pertinente, afinal o designer gráfico responsável pela criação de uma cédula - aqui extrapolando também para moedas - tem como objetivo expressar de maneira subjetiva uma mensagem da forma mais clara possível. Santos (2006) também analisou o real a partir da semiótica, relacionando os símbolos encontrados como metáfora da brasilidade.

Analisando esses últimos três autores, é possível refletir que os simbolismos presentes nas moedas são ao mesmo tempo propaganda construída para passar mensagens pré-determinadas e agentes passivos e ativos de formação de identidade. A 


\section{Revista de Arqueologia Pública}

história de um povo reflete-se nos símbolos numismáticos ao mesmo tempo em que os mesmos auxiliam a própria construção da identidade deste povo.

Em sua tese de doutorado, Amauri Junior apresenta um detalhado estudo sobre a etnografia do dinheiro, com foco nos projetos gráficos de papel-moeda no Brasil após 1960, identificando narrativas coletivas da brasilidade. Em um trecho do trabalho, ele apresenta informações sobre a construção simbólica da segunda série de moedas do real em uma entrevista com Glória Dias - que exerce um cargo de chefia na Casa da Moeda, tendo como uma de suas funções a escolha de elementos visuais para os projetos de cédulas e moedas. Parte dessa entrevista é transcrita abaixo:

[...] nós identificamos que o povo brasileiro estava carente de heróis. Carente de imagens que reforçassem a ideia do valor da história brasileira. [...] Recentemente havíamos passado pela experiência de um impeachment [...] A autoestima, a moral do brasileiro estava baixa em função disso. Era um momento apropriado para que o público visse, no seu dinheiro, aquelas figuras incontestes da história, aqueles que não tem mais como mudar a própria história (JUNIOR, 2008: 266).

Esse trecho é prova de que os símbolos nas moedas são construídos com objetivos claros de influenciar a população de maneira subjetiva, construindo e reconstruindo a visão do presente e do passado, da história, dos personagens ali cunhados, ou seja, influenciando a própria constituição de identidade de um povo.

Considerando o contexto histórico do Brasil quando foram cunhados os Dobrões na Casa da Moeda de Vila Rica na década de 20 do século XVIII, sem dúvida alguma é no terreno das ideias políticas, da propaganda e da religiosidade, onde é mais fecundo o serviço da Numismática à História. Cabe refletir sobre a significação da moeda na Minas setecentista, época e região de limitados meios de comunicação com a metrópole, em que o analfabetismo se estendia a numerosas camadas da população (FERRARO e KREIDLOW, 2004). A moeda é algo físico, palpável, objeto que abre portas e proporciona bem-estar. Nela pode-se contemplar a força e poder do Império e, ao mesmo tempo, cultivar a fé no cristianismo.

\section{Análise do contexto histórico do período de cunhagem dos dobrões}

A descoberta do ouro na região das Minas se deu no final do século XVII, acarretando um grande fluxo de pessoas para a região que posteriormente seria denominada Capitania das Minas Gerais (HOLANDA, 1999). Por volta de 1709, já havia 


\section{Revista de Arqueologia Pública}

mais de 30.000 pessoas na região ocupadas de atividades mineradoras, agrícolas e comerciais (BOXER, 1969).

O número de pessoas trabalhando com a extração do ouro continuou subindo com o passar dos anos, principalmente escravos. Através do registro das matrículas para a capitação de escravos, a década de 30 do século XVIII destaca-se pelo número avultado de negros inscritos, chegando à média de 98.500 escravos inscritos por ano no final da década. Assim, o ápice da produção aurífera das Gerais aconteceu entre aqueles últimos anos da década de 30 e primeiros da década seguinte do século XVIII (PINTO, 1979: 69).

Com a advento do ouro, teve-se início o tributo que ficou conhecido como Quinto, correspondente à quinta parte de todo o ouro extraído.

(...) podendo, pois, El Rei tirar à sua custa das minas que reserva para si os metais que são o fruto delas, atendendo aos gastos que para isso são necessários, e querendo animar aos seus vassalos ao descobrimento das ditas minas e a participarem do lucro delas, assentou, como se diz no título 34 do dito livro 2 das Ordenações, que todos os metais que se tirarem, depois de fundidos e apurado, paguem o quinto, em salvo de todos os custos (ANTONIL, 1976: 174).

A cobrança do Quinto era de extrema complexidade para a Coroa na região das Minas, dado o grande número de fraudes e a utilização do ouro em pó no comércio de escravos, gado etc. Entre as tentativas da coroa de cobrar o quinto ressalta-se a cobrança pelo número de bateias (utensílio utilizado para separação do ouro a partir da lavagem do cascalho retirado do leito do rio) e um Sistema de Finta (um valor fixo de 30 arrobas anuais).

Pela lei de 11 de fevereiro de 1719, D. João V determinou que erguessem Casa de Fundição nas Minas, fato que gerou a chamada Revolta de 1720 em Vila Rica (FIORAVANTE, 2010). Por causa dos motins, D. João $V$ decidiu criar uma capitania autônoma de Minas Gerais, desligando-a de São Paulo, em 1721. A inauguração da Casa de Fundição e da Moeda de Vila Rica se deu oficialmente somente em 1724. A partir de $1^{\circ}$ de fevereiro de 1725, todo o ouro das lavras devia ser entregue nas Casas de Fundição, onde haveria o desconto dos $20 \%$ do ouro em pó, sendo o resto fundido em uma barra e entregue ao minerador com uma guia, podendo ser levado para fora da capitania (RENGER, 2006). Não se poderia levar para fora daquela região o ouro em pó, que só seria utilizado no comércio local. Tal método não evitou a evasão fiscal, contudo aumentou a arrecadação da Coroa (SANTANA, 2010: 69).

O quinto acabou sendo substituído por outro imposto, a Capitação: uma cobrança mais 


\section{Revista de Arqueologia Pública}

ampla e equitativa do que o quinto real. Boxer (2000) reflete que foi a maneira alarmante pela qual o contrabando e a falsificação do ouro floresceram durante a década de 17251735 a razão para a comutação do quinto. Um bom exemplo sobre a intensidade de falsificação de moedas nas Minas setecentistas é dado por Guimarães (2008) ao descrever uma ilícita Casa da Moeda no Vale do Paraopeba, criada no fim dos anos de 1720 . Na mesma linha, segundo Campos, "Os trabalhos que abordam a implantação do sistema de capitação em Minas são quase unânimes em afirmar que a razão da mudança fora o grande contrabando e a falsificação de barras e moedas, e o volume crescente de ouro extraído" (CAMPOS, 2002: 339).

A Casa da Moeda de Vila Rica seria extinta pouco depois, em 7 de abril de 1734, quando também foi anunciado ainda que o ouro amoedado seria recolhido, tendo curso para o futuro apenas o ouro em barras, em folhetas, ou em pó (BARCELOS, 2013).

Assim, em uma época de grande produção de ouro na Capitania de Minas Gerais, quando eram frequentes o contrabando de ouro e as falsificações de moedas, a série de moedas Dobrões foi cunhada na recém-inaugurada Casa da Moeda de Vila Rica entre os anos de 1724 e 1727.

Segundo CHAVES (1956), a moeda de $20 \$ 000$ da série, que passou a ser denominada Dobrão, andou por muito tempo na linguagem popular como moeda rica e nobre e servia a grandes avaliações de propriedade e cômputo de fortunas avultadas. Segundo Gallas (2007), com um dobrão era possível comprar 190 litros de azeite, 9.600 ovos, ou até 12 bois na Capitania de Minas Gerais. Com quatro dobrões, era possível adquirir uma escrava jovem. Já o custo com salários das Casas de Fundição e Moeda de Vila Rica era de cerca de 218 dobrões $^{3}$ (AHU, 1729).

Apesar do valor cunhado do Dobrão ter sido de $20 \$ 000$ reis, seu valor oficial de circulação era de $24 \$ 000$ reis. Tal regra valeu-se para toda a série de dobrões, que circulavam sempre com o valor de $20 \%$ de acréscimo. Assim, as moedas cujo valor de face cunhado era de $10 \$ 000$ réis, $4 \$ 000$ réis, $2 \$ 000$ réis, $1 \$ 000$ réis e 400 réis circulavam com os respectivos valores, $12 \$ 000$ réis, $4 \$ 800$ réis, $2 \$ 400$ réis, $1 \$ 200$ réis e 480 réis.

Da série dos dobrões, as chamadas Moedas e Meia-Moedas, de valor de circulação de $4 \$ 800$ e $2 \$ 400$ respectivamente, eram a principal unidade de compra, especialmente na Metrópole.

[...] Era frequente o dizer "isso vale tantas moedas". Por ser a mais

${ }^{3} 3.000$ oitavas de ouro $\times 3,5859 \mathrm{~g}$ por oitava $=10.757,7 \mathrm{~g} .1$ Dobrão de $20 \$ 000$ possui $53,78 \mathrm{~g}$ com grau de pureza de $91,7 \% .10 .757,7 \mathrm{~g} /(53,78 \times 91,7 \%)=218,14$ dobrões. 


\section{Revista de Arqueologia Pública}

usada nas transações, empregou-se o nome em tudo que valia ou se julgava que valia, a sério ou por ironia. Porque um bom cavalo fora avaliado em cem moedas, uma mulher imponente e bem apresentada era "cavalo de cem moedas" CHAVES (1956: 53).

Entre os anos de 1724 a 1727, segundo Carrara (2010), foram cunhadas 432.769 moedas da série dobrões. De acordo com o mesmo autor, as moedas de valor igual ou superior a $4 \$ 800$ destinavam-se ao pagamento ao Reino e não à circulação interna na capitania. Ou seja, cerca de $90 \%$ dos dobrões acabaram com a coroa portuguesa.

Em valores atuais do ouro ( $\mathrm{R} \$ 148,90 / \mathrm{g}$, março/2016), a série dobrões colocou no mercado cerca de 2,17 bilhões de reais em ouro. Foram 14,6 toneladas de ouro em moedas, que com o acréscimo de valor de $20 \%$, circularam por cerca de 2,60 bilhões de reais em valore atuais. Ressalta-se que as Casas de Fundição e Moeda de Vila Rica cunharam mais moeda do que as Casas de Moeda de Lisboa e do Rio de Janeiro juntas entre 1724 e 1735, mostrando o papel de destaque que Minas Gerais exercia na época (CARRARA, 2010).

\section{Análise dos símbolos presentes na série de moedas do tipo dobrão}

No anverso do Dobrão é apresentado o escudo das armas portuguesas sob coroa (figura 1). A borda inferior do escudo termina em arco contracurvado, nos moldes do escudo do tipo francês. O escudo em questão é apresentado na figura 2 a seguir. $O$ dobrão apresenta a esquerda ao escudo o valor (20.000 reis) e a direita cinco florões (quadrifólios ou tetrapétalos com âmago). Ao redor, a inscrição IOANNES. V. D. G. PORT. ET. ALG. REX.

Por intermédio da heráldica - ciência e arte de descrever os brasões de armas ou escudos - é possível conhecer mais profundamente o escudo das armas presente nos Dobrões. Ele é composto por cinco escudetes formando uma cruz, sobrecarregados cada um com cinco besantes dispostos na forma de cruz de Santo André. A utilização do ícone da cruz indica a forte religiosidade cristã dominante na época em Portugal. Os cinco escudetes representam as cinco chagas de Cristo, em alusão à batalha medieval pela independência em Ourique, na qual Cristo teria aparecido para Afonso Henriques e lhe prometido a vitória, se adotasse suas chagas como suas armas (GALLAS, 2007: 47).

Os besantes dificilmente são visíveis nos dobrões, dado sua pequena dimensão e a tecnologia de cunhagem da época. Contudo, trata-se de círculos ou discos chatos, imitando a antiga moeda bizantina que levava o mesmo nome de besante. Sua simbologia 


\section{Revista de Arqueologia Pública}

remete aos cavaleiros que haviam realizado viagens à Palestina. Segundo Morujão (2012), os cinco escudetes do brasão somados aos vinte e cinco besantes representam as 30 moedas de prata que Judas Iscariotes recebeu ao trair Jesus. Novamente uma simbologia religiosa subliminar, ainda que contestado o real significado dos besantes visto que seu número variou diversas vezes conforme verificado pelos selos régios e pela própria numismática.

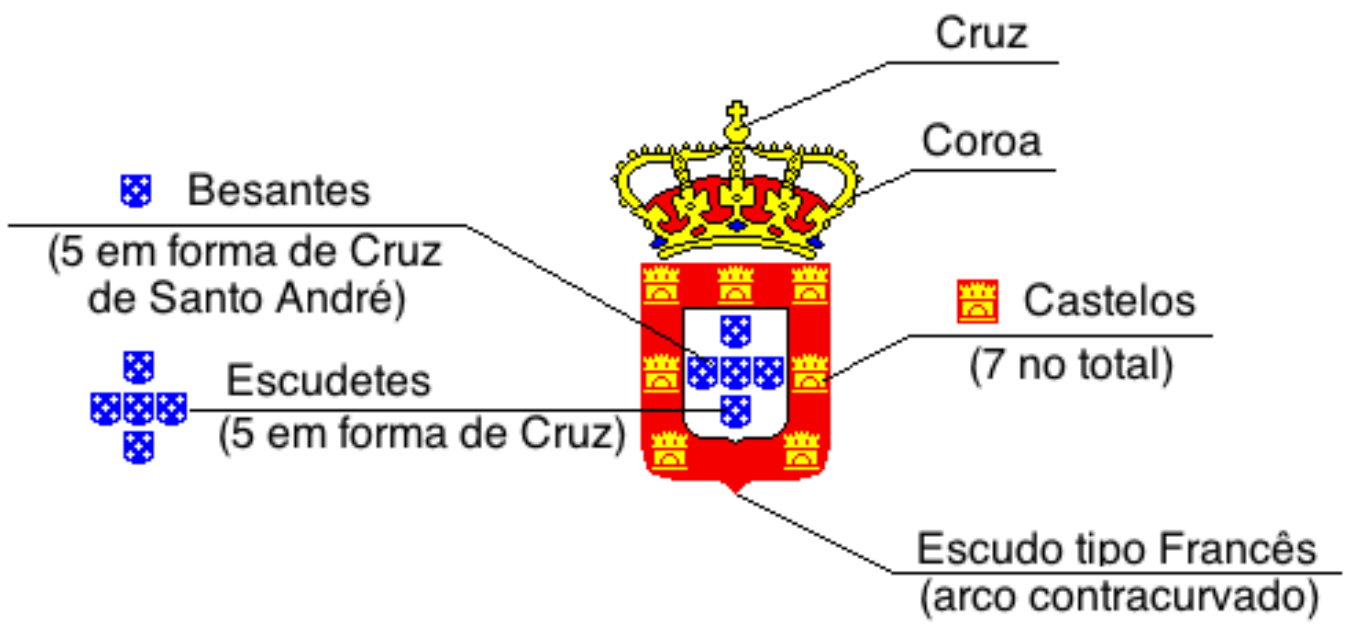

Figura 2: Indicativo dos elementos constituintes do escudo das armas portuguesas no reinado de $D$. João V. FONTE: Elaborada pelo Autor, 2015.

A bordadura do brasão é detalhada com sete castelos. Cada castelo é composto por um edifício principal, mostrando um portão fechado, em cima da qual estão três torres com ameias (FILIPE, 2010: 181). Os castelos usualmente remetem a representações de vitórias de D. Afonso III sobre os mouros durante a conquista de Algarve, concluída em 1249, seriam eles: Albufeira, Aljezur, Cacela, Castro, Marim, Estômbar, Paderne e Fortaleza de Sagres. Contudo, tal simbologia é questionada visto que a própria bandeira de D. Afonso III não possuía sete castelos e que o número de castelos variou durante diversos reinados. Outra hipótese sobre a origem e representação dos castelos remete aos laços desse governante com Castela. Em ambas as representações o poder e a nobreza estão sempre presentes (GOMES e MAGRO, 2007).

A coroa é símbolo de soberania temporal. Nos dobrões, a coroa real é do tipo fechada com cinco arcos visíveis. Essa coroa tomou tal forma no início do período da regência de D. Pedro II em Portugal, após o golpe de Estado que afastou D. Afonso VI do trono em 1667. O aumento do número de arcos (de 3 para 5) simboliza um novo reforço da autoridade régia. O coroa presente nos dobrões apresenta ainda uma cruz em seu topo, em referência à devoção a fé cristã. Apesar de $\mathrm{D}$. João $\mathrm{V}$ utilizar o símbolo da coroa real nas 


\section{Revista de Arqueologia Pública}

bandeiras, numismática e armas de seu reinado, ele não foi coroado quando subiu ao poder em 1707. Seguindo uma tradição iniciada por seu avô D. João IV, ele coroou em seu lugar uma estátua de Nossa Senhora da Conceição como Rainha e Padroeira do Reino.

A inscrição IOANNES. V. D. G. PORT. ET. ALG. REX significa “João V, pela graça de Deus, Rei de Portugal e Algarves", em referência à titulação régia de D. João V. Esta, contudo, era na realidade mais abrangente do que a inscrição no dobrão. A titulação completa, que já era utilizada desde Dom Manuel I, era "pela Graça de Deus, Rei de Portugal e dos Algarves, d'Aquém e d'Além-Mar em África, Senhor de Guiné e da Conquista, Navegação e Comércio da Etiópia, Arábia, Pérsia e Índia etc" (PEGORARO, 2014). O Brasil ainda não constava na titulação dos reis de Portugal, fato que só se deu em 1815 quando da elevação do Brasil à Reino dentro do Império Português, no reinado de D. Maria I (1777-1816) (ARAÚJO, 1992).

Conforme pode ser observado, tanto a coroa quando a titulação régia utilizada por D. João $V$ fazem referência à religião católica. $A$ proximidade de $D$. João $V$ ao catolicismo dava-se em um período histórico onde era grande a importância internacional da Santa Sé frente a ameaça do Império Otomano.

O reverso do Dobrão apresenta ao redor da Cruz de Cristo (Figura 3) quatro letras monetárias $\mathrm{M}$, a era (ano) e a inscrição IN HOC SIGNO VINCES (MOEDAS DO BRASIL, 2014). A Cruz de Cristo é um símbolo intrínseco de Portugal, sendo uma derivação da Cruz da Ordem dos Templários. Ela não é uma, mas sim duas cruzes: uma branca e outra vermelha (aqui representada pela cor preta). Seu misticismo envolve o incentivo à coragem e esforço pela vitória.

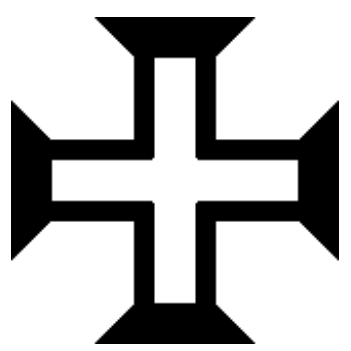

Figura 3: Cruz de Cristo presente no reverso da série de moedas Dobrão. FONTE: Elaborada pelo Autor, 2015.

Nas quatro diagonais da Cruz de Cristo é indicado a letra monetária "M" nas moedas da série Dobrões, em referência à cunhagem ter sido realizada na Casa da Moeda de Minas Gerais. Moedas de ouro cunhadas no mesmo período de D. João V, o Magnânimo, na Casa da Moeda do Rio de Janeiro (1707-1730) e na Casa da Moeda da Bahia (1714-1727) tiveram as respectivas letras monetários " $R$ " e " $B$ " indicadas nas mesmas 


\section{Revista de Arqueologia Pública}

diagonais da Cruz de Cristo.

A inscrição ao redor da Cruz de Cristo significa "Com esse sinal vencerás", em uma clara alusão à lenda do Rei Afonso I de Portugal que teria visto o símbolo na Batalha de Ourique no ano de 1.139 e passou a utilizá-lo como símbolo nacional e como lema. Uma outra interpretação é que se trata da tradução latina da frase grega "Por este sinal conquistarás" em alusão à lenda da visão de Constantino em 312.

\section{Religiosidade e poder}

A criação de uma Casa de Fundição e Moeda nas Minas foi uma necessidade devido ao crescimento da produção de ouro na região. Assim, mesmo após a Revolta de 1720, D. João V decidiu pela criação de uma capitania específica para a região, que se passou a chamar Minas Gerais. Além disso, instaurou as Casas de Fundição e da Moeda de Vila Rica em 1724, atual Ouro Preto. Lá foi cunhada a série de moedas de ouro dos Dobrões, além de outras moedas.

A maior moeda dessa série levou também o seu nome e passou-se a ser designada como Dobrão. Trata-se de uma moeda de $20 \$ 000$, que tinha valor de circulação de $24 \$ 000$. É a moeda de maior valor intrínseco já circulada no mundo, com 53,78 g. Só de ouro, ela tem um valor atual de mais de $R \$ 7$ mil. A cunhagem dessa moeda é uma clara demonstração de poder exercido por Portugal. A maior parte dessas moedas teve como destino a metrópole e poucas realmente circularam em Minas ou no Brasil. Portugal queria mostrar ao mundo sua grandeza e riqueza e escolheu a fabricação de uma moeda de grande valor como sua propaganda política. D. Manuel já havia usado a mesma estratégia em Portugal no passado (GALLAS, 2007).

Muitos dos ícones presentes nessa série de moedas remetem à religiosidade católica: duas cruzes (a de malta no reverso e uma no topo da coroa no anverso), os cinco escudetes representando as cinco chagas de Cristo e os 25 besantes que somados os cinco escudetes representam as 30 moedas que Judas recebeu ao trair Jesus são exemplos simbólicos que demonstram a importância da religiosidade no Reino Português.

Ainda sobre a religiosidade, a história por trás da coroa de D. João V é intrigante. Assim como seu avô e seu pai, ele não foi coroado quando se tornou rei. Na ocasião ele preferiu coroar uma imagem de Nossa Senhora da Conceição como Rainha e Padroeira do Reino. Curiosamente, essa proximidade da metrópole com a Nossa Senhora da Conceição e, consequentemente, do povo brasileiro com a mesma, acabou por influenciar a construção da identidade nacional. Em 1717, uma imagem dela foi encontrada por pescadores, por isso 


\section{Revista de Arqueologia Pública}

foi lhe atribuído o título de "Aparecida". Hoje a Nossa Senhora da Conceição Aparecida é conhecida como Rainha e Padroeira do Brasil.

Além disso, a inscrição "Com esse sinal vencerás" também possui cunho religioso, indicando o poder de Portugal em batalhas pelo fato de contar com o apoio divino em suas armas.

A propaganda de poder é também refletida em outros ícones das moedas de dobrões. O brasão de armas contando com sete castelos rementem a vitórias históricas portuguesas de um passado remoto, em uma clara referência a uma história de longa data de força e poder. A própria inscrição do anverso "João $V$, pela graça de Deus, Rei de Portugal e Algarves" remete a seu poder não só em Portugal, mas no Reino Unido de Algarves. Ademais, novamente há referência em relação ao poder ser vinculado à religião católica.

A série de dobrões tornou-se icônica no imaginário brasileiro ao longo de vários séculos. Ela remete a uma época de grandes riquezas e prosperidade. Os dobrões refletem toda uma sociedade colonial e o poder de sua metrópole. Seus símbolos ao mesmo tempo em que representam uma era influenciaram a formação da identidade do povo brasileiro. Ainda hoje é possível achar itens sendo vendidos com as imagens dos dobrões, como camisetas ou réplicas das próprias moedas. Esse fato por si só demonstra o poder da iconografia numismática em tornar-se e permanecer parte integrante da cultura de um povo, mesmo após quase 300 anos.

\section{Considerações finais}

Seja como símbolo de poder ou de religiosidade, de uso como propaganda do reino ou riqueza, as moedas de ouro do Brasil colonial contam uma história de influência diária no cotidiano do Brasil. Nenhuma delas é tão simbólica quanto os Dobrões cunhados nas Minas setecentistas. Essas moedas lapidaram a identidade do povo brasileiro, influenciando-a à submissão ao poder do Rei e ao cristianismo, ao mesmo tempo que enviavam a mensagem subliminar de riqueza sem igual e prosperidade contínua.

Sugere-se como continuidade de estudo a pesquisa comparativa entre os símbolos dos Dobrões com os da série de Escudos, cunhados também na Casa da Moeda de Vila Rica. Em tais moedas deu-se início a cunhagem da imagem da esfinge do Rei, de modo a fortalecer ainda mais seu poder junto aos seus súditos. 


\section{Revista de Arqueologia Pública}

\section{Referências bibliográficas}

AHU, Cons. Ultra. - Brasil/MG, cx. 14, doc. 46. Representação: dos oficiais da Câmara de Vila Rica a respeito das rendas de mais de três mil oitavas de ouro despendidas com os salários dos oficiais das Casas de Fundição e Moeda e pedindo que não seja nomeado José Boaventura Vieira para carcereiro de Vila Rica. 12/07/1729.

ANTONIL, André João. Da obrigação de pagar a El-Rei nosso senhor a quinta parte do ouro que se tira das minas do Brasil. In: ANTONIL, André João (Org.) Cultura e opulência do Brasil por suas drogas e minas. São Paulo. 3 ed. p. 163-181.1976.

ARAÚJO, A. C. B. O Reino Unido de Portugal, Brasil e Algarves, 1815/1822. Revista de História das Ideias, v. 14, p. 233-261, 1992.

BARCELOS, R. Casas de fundição e da moeda no Brasil e em Portugal: purificar o ouro, apurar as técnicas. População e Sociedade. CEPESE, Porto. Vol. 21; p. 143-163, 2013.

BERG, T. J. A construção simbólica do espaço através da representação geográfica nos símbolos nacionais. Rio Claro: Universidade Estadual Paulista, p. 192, 2014. (Tese de Doutorado. Programa de pós-graduação em Geociências e Ciências Exatas) Universidade Estadual Paulista, Rio Claro, 2014.

BLACKBURN, Mark. Crosses and Conversion: The Iconography of the Coinage of Viking York ca. 900'. In: JOLLY, K.L; KARKOV, C.E. e KEEFER, S.L. (Org.). Cross and Culture in Anglo-Saxon England: Studies in Honour of George Hardin Brown, Morgantown: West Virginia University Press, 2008.

BLOCH, M. e PARRY, J. Introduction: Money and the Morality of Exchange. In: BLOCH, M e PARRY, J. (Org.). Money and the Morality of Exchange. Cambridge: Cambridge University Press, 1989.

BOXER, C. R. A Idade de Ouro do Brasil. São Paulo, Editora Cia Editora Nacional, 1969.

A Idade de Ouro do Brasil: Dores de crescimento de uma sociedade colonial. Rio de Janeiro, Editora Nova Fronteira, 2000.

CAMPOS, M. V. Governo de mineiros: "de como meter as minas numa moenda e beberIhe o caldo dourado" (1693-1737). São Paulo: Universidade de São Paulo - FFLCH, p. 479, 2002. (Tese de Doutorado. Programa de pós-graduação em História) - Universidade de São Paulo, São Paulo, 2002.

CARLAN, C. U. Arte monetária romana: reflexo de uma propaganda. I Encontro de História da Arte, IFCH/UNICAMP. Campinas, p. 74-78, 2005.

. A História do Brasil através da Moeda: A Primeira Casa da Moeda Brasileira

- Bahia 1964. Revista Aulas. Gênero, Subjetividade e Cultura Material, UNICAMP. Campinas, p.1-12, 2006.

Simbologia, numismática e iconografia: a imagem como documento. Almanaque Multidisciplinar de Pesquisa, Universidade Unigranrio. Ano II. V. 1, n. 1, 2015.

CARRARA, A. A. A moedação e oferta monetária em Minas Gerais: as casas de Fundição e Moeda de Vila Rica. Varia História. Belo Horizonte, Vol. 26, No 43, p. 217-239, 2010. À vista ou a prazo: comércio e crédito nas Minas setecentistas. Juiz de 


\section{Revista de Arqueologia Pública}

Fora: editora da UFJF, 2010.

CERULO, K. A. Sociopolitical Control and the Structure of National Symbols: An Empirical Analysis of National Anthems. Social Forces, Chapel Hill, v. 68, n. 1, p. 76-99, 1989.

CHAVES, L. A moeda na etnografia: as moedas com aproveitamento e adaptação a usos e costumes populares em Portugal. Sociedade Portuguesa de Numismática. Porto, p. 11$56,1956$.

COIMBRA, A.V. Noções de Numismática II. Revista de História, vol. 12, n² 26, 1956.

FERRARO, A. R. e KREIDLOW, D. Analfabetismo no Brasil: configuração e gênese das desigualdades regionais. Educação e Realidade. V. 2, n. 29, 2004.

FILIPE, S. B. O Estado da Arte da Marca Portugal. Gestin. Ano VIII, N.o 8, p. 177-194, 2010.

FIORAVANTE, F. A governança das Minas e o processo de implantação do poder régio nas terras do ouro na primeira metade do século XVIII. Anais do Seminário Internacional Justiça, Administração e Luta Social: Dimensões do Poder em Minas. Mariana, v. 1. p. 1-20, 2010.

FLORENZANO, M.B.B. Fontes sobre a origem da moeda: apresentação crítica. Rev. do Museu de Arqueologia e Etnologia, São Paulo, n. 11, p. 201-211, 2001.

GALLAS, A. O. G. As moedas contam a história do Brasil. São Paulo: Magma Editora Cultural, 2007.

GOMES, A.; MAGRO, F. A. Moedas portuguesas e do território que é hoje Portugal: catálogo das moedas cunhadas para o Continente e llhas Adjacentes, para os territórios do Ultramar e Grão-Mestres portugueses da Ordem de Malta. Lisboa: Editora Associação Numismática de Portugal, 2007.

GONÇALVES, Cléber Baptista. Casa da Moeda do Brasil: 290 anos de história, 1694/1984. Casa da Moeda do Brasil. Rio de Janeiro: Editora Casa da Moeda Imprita, 1984.

GOOCH, M. L. Money and Power in the Viking Kingdom of York. c. 895-954, Durham: Durham University, p. 371, 2011. (Tese de Doutorado. Programa de pós graduação em História) - Durham University, Durham, 2011.

GUIMARÃES, A. R. Moedas falsas e negócios: o território do lícito e do ilícito nas Minas setecentistas. Revista de Humanidades. Anais do II encontro Internacional de História Colonial, UFRN, Natal, V.9, n. 24, 2008.

JUNIOR, A. F. S. Uma etnografia do dinheiro: os projetos gráficos de papel-moeda no Brasil após 1960. Rio de Janeiro: Universidade do Estado do Rio de Janeiro, p. 285, 2008. (Tese de Doutorado. Programa de pós graduação em Ciências Sociais), Universidade do Estado do Rio de Janeiro , Rio de Janeiro, 2008.

HOLANDA, S. B. Raízes do Brasil. São Paulo: Editora Companhia das Letras, 1999.

MAGNUS, B. Roman Gold and the Development of the Early Germanic Kingdoms. Kungl. Vitterhets Historie och Antikvitets Akademien. Stockholm, p. 128-164, 2001.

\begin{tabular}{|l|l|l|l|l|l|l|}
\hline Rev. Arqueologia Pública & Campinas, SP & v. 10 & n. 2 & p. 69-85 & JUN. 2016 & ISSN 2237-8294
\end{tabular}




\section{Revista de Arqueologia Pública}

MAUAD, A. M. História, iconografia e memória. In: SIMSOM, O. V. (Org.). Os desafios contemporâneos da História Oral, Campinas (Unicamp): Centro de Memória da Unicamp, 1997.

MOEDAS DO BRASIL, Catálogo das Moedas do Brasileiras. Moedas da série Dobrões, Vila Rica - Ouro e Moedas da série Escudos, Vila Rica - Ouro. Disponível em: $<\mathrm{http}: / /$ www. moedasdobrasil.com.br/series.asp? $\mathrm{a}=0 \& \mathrm{v}=0 \& \mathrm{t}=0 \& \mathrm{~s}=43 \& \mathrm{~m}=>$. Acessado em $16 / 03 / 2016$.

MORUJÃO, M. R. B. A sigilografia portuguesa em tempos de Afonso Henriques. Medievalista. №11, ISSN 1646-740X, 2012.

PEGORARO, J. W. Oficiais a serviço do Império Português: A estrutura jurídicoadministrativa lusitana no século XVIII. Revista Jurídica. v. 2, n. 35, p. 1-23, 2014.

PINTO, V. N. O ouro brasileiro e o comércio anglo-português. São Paulo: Editora Nacional, 1979.

RAMOS, M. C. Cruzeiro: O meio circulante brasileiro como ideologia e propaganda do Estado Novo. XV Encontro Regional de História de ANPUH-RIO. São Gonçalo, Rio de Janeiro. ISBN 978-85-65957-00-7, 2012.

RENGER, F. E. . O quinto do ouro no regime tributário nas Minas Gerais. Revista do Arquivo Público Mineiro, v. 42, p. 90-105, 2006.

RINALDI, R; NERY, V. C. A. O Real significado: análise semiótica das cédulas do plano real. Revista IDEA. V.1, n.1, 2009.

SANTANTA, E. Evasão fiscal e tributação do ouro nas Minas Gerais do século XVIII. Revista Urutágua. № 20. p. 65-74. ISSN 1519.6178, 2010.

SANTOS, S. A. O discurso do Real: metáfora da brasilidade. Estudos Linguísticos XXXV, p. 1802-1807, 2006.

SILVERINHA, M. J. Moeda e Construção Europeia: Uma abordagem identitária. III SOPCOM, VI LUSOCOM e II IBÉRICO, Universidade da Beira Interior, Covilhã, Portugal. Vol. IV, p. 491- 501, 2004. 